\title{
Disrupting reconsolidation: Pharmacological and behavioral manipulations
}

\author{
Marieke Soeter and Merel Kindt ${ }^{1}$ \\ Department of Clinical Psychology, University of Amsterdam, 1018 WB Amsterdam, The Netherlands
}

\begin{abstract}
We previously demonstrated that disrupting reconsolidation by pharmacological manipulations "deleted" the emotional expression of a fear memory in humans. If we are to target reconsolidation in patients with anxiety disorders, the disruption of reconsolidation should produce content-limited modifications. At the same time, the fear-erasing effects should not be restricted to the feared cue itself considering that fear generalization is a main characteristic of anxiety disorders. In Experiment $\mathrm{I}$ and Experiment $\mathrm{I}^{\mathrm{b}}$, we addressed these issues using a within-subject differential startle fear conditioning paradigm and a test of fear generalization. In Experiment II, we tested whether a behavioral approach targeting the reconsolidation through extinction learning was also effective in weakening the original fear memory. A behavioral procedure is evidently preferred over drug manipulations provided that similar effects can be obtained. Here, the extinction procedure subsequent to retrieval did not "erase" the emotional expression of the fear memory as the retrieval techniques (i.e., reminder shocks and reacquisition) unveiled a return of the startle fear response to the fear-relevant stimuli. In contrast, $\beta$-adrenergic receptor blockade during reconsolidation selectively deleted the fear-arousing aspects of the memory (i.e., startle fear response) along with its category-related information. The pharmacological manipulation rendered the core memory trace too weak to observe fear generalization after successful reacquisition. Hence, relearning following the disruption of reconsolidation seems to be qualitatively different from initial learning. Our findings demonstrate that disrupting reconsolidation by pharmacological manipulations, although selective, undermines the generalization of fear, a key feature of anxiety disorders.
\end{abstract}

[Supplemental material is available for this article.]

The phenomenon of reconsolidation, the stabilization of a memory after retrieval, enables the modification of memory representation (Nader et al. 2000). Considerable evidence in animals now indicates that blockade of the process of reconsolidation by pharmacological manipulations produces amnesia for the original fear learning (Nader et al. 2000; Dudai 2006; Tronson and Taylor 2007; Nader and Hardt 2009). We previously demonstrated that disrupting reconsolidation by administering propranolol prior to memory reactivation resulted in erasure of the fear response in humans (Kindt et al. 2009), an effect that persisted over time (Soeter and Kindt 2010). However, the typical differential fear conditioning paradigm (i.e., CS1-US vs. CS2) did not allow any inference about the nature of the fear memory erasure. Even though animal studies showed selective amnesia for the specific fear association (i.e., CS1-US) (Doyère et al. 2007), studying humans necessitates systemic (as opposed to intra-amygdala) drug administration. Accordingly, the erasure of the fear response could also have resulted from a more diffuse effect of the propranolol manipulation by reducing the fear-provoking aspects of the aversive consequence itself (US) (Kindt et al. 2009; Soeter and Kindt 2010). In considering clinical implications, disrupting reconsolidation should not radically alter functional reactions to potentially dangerous situations (US), but selectively weaken the underlying maladaptive fear association (CS1-US). On the other hand, disrupting reconsolidation should not be restricted to the feared cue itself considering that fear generalization is a main characteristic of anxiety disorders (Lissek et al. 2008). Previously, it was shown in rats that higher-order (i.e., associated)

${ }^{1}$ Corresponding author.

E-mail m.kindt@uva.nl; fax 31206391369.

Article is online at http://www.learnmem.org/cgi/doi/10.1101//m.2148511. memories undergo reconsolidation when reactivated by the primary (i.e., first-order) fear association (Dębiec et al. 2006). A key question is whether the fear-erasing effects spread to categoryrelated information not previously associated with the originally feared stimulus.

Irrespective of the nature of the fear memory erasure, the systemic drug manipulation specifically targeted the emotional expression of the memory (Kindt et al. 2009; Soeter and Kindt 2010). That is, $\beta$-adrenergic receptor blockade during memory reactivation resulted in the persistent erasure of the startle fear response, without affecting the expectancy ratings and skin conductance discrimination (Soeter and Kindt 2010). Electrodermal conditioning seems to primarily reflect the cognitive level of contingency learning (i.e., declarative knowledge) (Weike et al. 2007), based on the functional integrity of the hippocampal complex (Squire et al. 2004). Conversely, human startle potentiation is considered to be a reliable and specific index of fear (Hamm and Weike 2005), directly connected with, and modulated by, the amygdala (Davis 2006). These data thus demonstrated that memories can undergo reconsolidation at one level (i.e., amygdalar fear memory), simultaneously leaving the hippocampal-dependent declarative memory untouched (Kindt et al. 2009; Soeter and Kindt 2010). In principle, all memory systems should be subject to disrupting reconsolidation given the appropriate situations (Lee 2009). In particular, the labilization of a memory appears to be crucially dependent upon the informational value provided during retrieval (Lee 2009; D Sevenster, T Beckers, and $\mathrm{M}$ Kindt, unpubl.). As a result, the partial reinforcement scheme during acquisition may have prevented the single unreinforced reactivation trial from learning (i.e., memory updating) at the propositional level (Kindt et al. 2009; Soeter and Kindt 2010). Indeed, a recently introduced behavioral approach targeting the 
reconsolidation of fear memory demonstrated that multiple unreinforced presentations allowed for updating of the more cognitive component of emotional memory in humans (Schiller et al. 2010). That is, an extinction procedure performed within the window of reconsolidation resulted in the persistent erasure of the skin conductance response (i.e., declarative knowledge). Even though animal studies showed a destabilization of the fear memory trace in the lateral amygdala by behaviorally disrupting reconsolidation (Monfils et al. 2009; Clem and Huganir 2010), the effects on the emotional expression of fear memory in humans are unknown. Obviously, a behavioral procedure will be preferred over pharmacological manipulations provided that similar effects can be obtained. Hence, a crucial question is whether the behavioral disruption of reconsolidation also produces amnesia for the amygdalar startle fear response.

Here, we addressed these issues by using a within-subject differential fear conditioning procedure allowing selective reactivation of one of two categorically distinct fear associations sharing the same aversive outcome (Doyère et al. 2007; Schiller et al. 2010), two tests of fear recovery (i.e., reinstatement, reacquisition) and a test of fear generalization (Fig. 1). During acquisition (day 1), two fear-relevant stimuli (CS1, CS2) were repeatedly paired with an aversive electric stimulus (US), whereas a fear-irrelevant stimulus was not (CS3) (see Supplemental Fig. 1). We employed fear-relevant stimuli because they lead to a superior conditioning of aversive associations and are especially resistant to extinction learning compared with fear-irrelevant cues (Mineka and Öhman 2002; Lang et al. 2005). Moreover, given that most anxiety disorders are associated with these categories of stimuli, we are specifically interested in targeting stronger fear memory. One of the fear-relevant stimuli (CS2) served as control for the other fear-relevant stimulus (CS1). However, as fear-relevant stimuli are known to have an innate prepotency to elicit fear responses (Lovibond et al. 1994), we employed an additional fear-irrelevant control cue (CS3) to verify whether the procedure was capable of neutralizing fear responding. In Experiment I, all of the participants received single-blind an oral dose of $40 \mathrm{mg}$ of propranolol, a $\beta$-adrenergic receptor antagonist known to disrupt reconsolidation (Dębiec and LeDoux 2004; Kindt et al. 2009; Soeter and Kindt 2010), 90 min prior to selective reactivation of the CS1 memory (day 2). Conversely, in Experiment II, the participants were fear extinguished to both the CS1 and CS2 10 min after selective reactivation of the CS1 memory (within the reconsolidation window) (day 2) (Schiller et al. 2010). Memory retention of both the CS1 (CS1 vs. CS2; CS1 vs. CS3) and CS2 (CS1 vs. CS2; CS2 vs. CS3) was tested $24 \mathrm{~h}$ later (day 3 ). In order to maximize the likelihood of fear memory expression, reminder shocks were administered following (re)-extinction learning (day 3). The absence of a fear response by the behavioral provocation (i.e., reinstatement) suggests, but cannot prove, the absence of the underlying fear association. Reacquisition of fear was therefore further investigated as a measure of savings of the original fear associations. Generalization stimuli (G-CS1, G-CS2, G-CS3) (Supplemental Fig. 1) were presented to assess whether the fear-erasing effects would spread to category-related information. The conditioned fear response (CR) was measured as potentiation of the eyeblink startle reflex to a loud noise by electromyography of the right orbicularis oculi muscle. Startle potentiation taps directly in the amygdala and fear conditioning procedures yield highly reliable and robust startle potentiation (Davis 2006). Skin conductance responses and retrospective US-expectancy ratings were obtained to assess the more cognitive level of contingency learning (Weike et al. 2007) (i.e., declarative knowledge). The effects of disrupting reconsolidation on the declarative level were further investigated by measuring subjectively experienced distress through online VAS-ratings during each CS presentation.

\section{Results}

\section{Experiment I, Propranolol-Reactivation}

$\beta$-adrenergic receptor blockade during memory reactivation selectively erases the startle fear response along with its category-related information

Analysis of variance showed fear conditioning on day 1 by a significant increase of the differential startle response (i.e., simple contrasts: $\mathrm{CS}^{+}$vs. $\mathrm{CS}^{-}, \mathrm{CS}^{+}$vs. $\mathrm{CS}^{-}$) from trial 1 to trial 5 (stimulus $\times$ trial, $F_{(1,14)}=15.68, P=0.001, \eta^{2}=0.53 ; F_{(1,14)}=$ 19.23, $P=0.001, \eta^{2}=0.58$, respectively). We observed no difference in responding to the first trial of acquisition $\left(\mathrm{CS}^{+}\right.$vs. $\mathrm{CS}^{+}$vs. $\mathrm{CS}^{-}$) (stimulus, $F_{(2,13)}<1$ ) and fear responses to the reinforced stimuli $\left(\mathrm{CS}^{+}\right.$and $\left.\mathrm{CS}^{+}\right)$were equally acquired (stimulus $\times$ trial, $F_{(1,14)}<1$ ) (Fig. $2 \mathrm{~A}$ ). In addition, the absence of a significant decrease in startle responses (CS1 vs. noise alone, NA) from the last trial of acquisition to memory reactivation (day 2) demonstrates that the propranolol manipulation did not directly affect the expression of the previously acquired fear association (Kindt et al. 2009; Soeter and Kindt 2010) (stimulus $\times$ trial, $\left.F_{(1,14)}<1.47\right)$.

However, the administration of propranolol significantly decreased startle responses to the reactivated CS1 from the last trial of acquisition to the first extinction trial $48 \mathrm{~h}$ later (day 3) $\left(\mathrm{CS} 1\right.$ vs. CS3; stimulus $\times$ trial, $F_{(1,14)}=25.57, P<0.001, \eta^{2}=$ 0.65) (Fig. 2A), irrespective of the reactivated stimulus (i.e., spider vs. gun) (see Supplemental Results). In fact, conditioned fear responses were not only reduced but even eliminated, as we no longer observed a differential startle response to the first trial of extinction learning (day 3 ) (CS1 vs. CS3; $t_{(14)}<1$ ). Conversely,

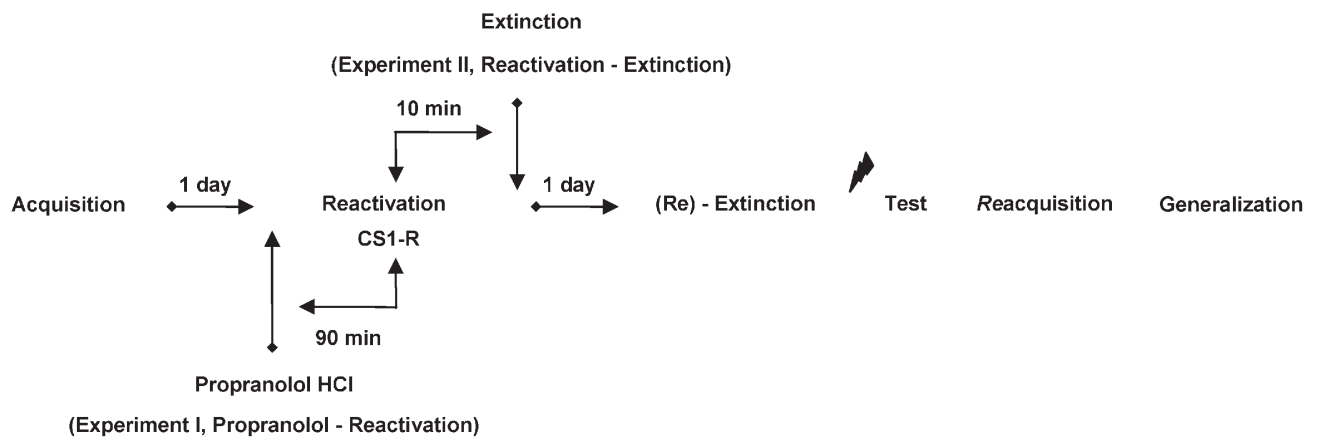

Figure 1. Schematic of the experimental design for Experiment I, Propranolol-Reactivation, and Experiment II, Reactivation-Extinction. 

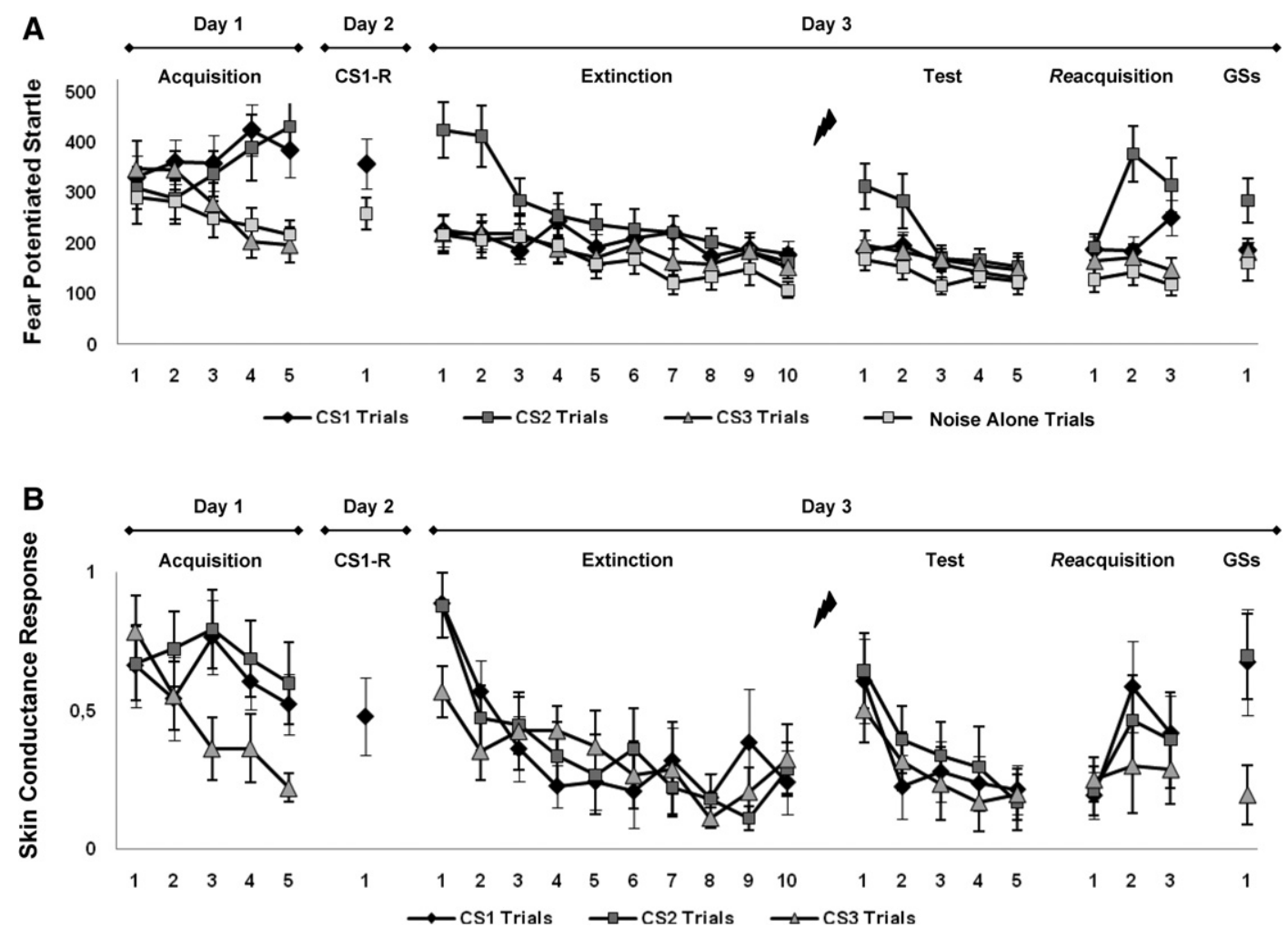

Figure 2. Experiment I, Propranolol-Reactivation. Selective erasure of a fear network. ( $A$ ) Mean startle potentiation to the fear conditioned stimuli (CS1 and CS2), the control stimulus (CS3), and noise alone (NA) trials during acquisition, memory reactivation, extinction-test, reacquisition, and generalization. In contrast to the startle fear response, we observed no effects of $\beta$-adrenergic receptor blockade during memory reactivation on (B) skin conductance conditioning. Error bars represent SEM.

startle responses to the nonreactivated CS2 remained stable from acquisition to extinction $48 \mathrm{~h}$ later (CS2 vs. CS3; stimulus $\times$ trial, $\left.F_{(1,14)}<1\right)$. Further comparisons between the two conditioned stimuli indeed showed intact fear responses to the nonreactivated CS2 contrary to the reactivated CS1 (stimulus $\times$ trial, $\left.F_{(1,14)}=15.74, P=0.001, \eta^{2}=0.53\right)$, indicating that the propranolol manipulation selectively affected the reactivated fear association.

Given that responses to the reactivated CS1 were already eliminated (day 3), we observed no differential change in startle responses (CS1 vs. CS3) over the course of extinction learning (trial 1 vs. trial 10; stimulus $\times$ trial, $F_{(1,14)}<1$ ) (Fig. $2 \mathrm{~A}$ ). In contrast, startle responses to the nonreactivated CS2 significantly decreased from the first extinction trial to the last trial of extinction learning (CS2 vs. CS3; stimulus $\times$ trial, $F_{(1,14)}=10.79, P<$ $\left.0.01, \eta^{2}=0.44\right)$.

The reminder shocks following extinction learning (day 3) did not uncover any fear response to the reactivated CS1 (CS1 vs. CS3; stimulus $\times$ trial, $\left.F_{(1,14)}<1.44\right)$, whereas a recovery of fear to the nonreactivated CS2 was observed from the last trial of extinction to the first trial at test (CS2 vs. CS3; stimulus $\times$ trial, $\left.F_{(1,14)}=6.85, P<0.05, \eta^{2}=0.33\right)$. Indeed, a significant reinstatement effect to the nonreactivated CS2 as compared to the reactivated CS1 was found (stimulus $\times$ trial, $F_{(1,14)}=11.02, P<0.01$, $\eta^{2}=0.44$ ) (Fig. 2A). Moreover, re-extinction learning (trial 1 vs. trial 5) following the reminder shocks again significantly reduced fear responses to the nonreactivated CS2 (CS2 vs. CS3; stimulus $\times$ trial, $\left.F_{(1,14)}=14.74, P<0.01, \eta^{2}=0.51\right)$. As responses to the reactivated CS1 remained eliminated, no differential change in startle responding (CS1 vs. CS3) over the course of re-extinction learning was observed (stimulus $\times$ trial, $F_{(1,14)}<1$ ).
In contrast to the rapid reacquisition of the fear response to the nonreactivated CS2 from trial 1 to trial 2 (CS2 vs. CS3; stimulus $\times$ trial, $\left.F_{(1,12)}=13.54, P<0.01, \eta^{2}=0.53\right)$, we observed no rapid reacquisition learning to the reactivated CS1 (CS1 vs. CS3; stimulus $\times$ trial, $\left.F_{(1,12)}<1\right)$. Further comparisons between the two feared cues indeed showed recovered startle fear responses to the nonreactivated CS2 contrary to the reactivated CS1 (trial 1 vs. trial 2) (stimulus $\times$ trial, $F_{(1,13)}=14.28, P<0.01, \eta^{2}=0.52$ ) (Fig. 2A). Notably, the differential change in startle responses to the reactivated stimulus (CS1 vs. CS3) over the course of reacquisition learning (trial 1 vs. trial 2 vs. trial 3) exactly followed the response pattern obtained to the first reinforced trials during acquisition (trial 2 vs. trial 3 vs. trial 4 ) (day 1 vs. day 3; stimulus $\times$ trial, $\left.F_{(2,12)}<1.67\right)$, indicating that there were no savings of the original fear association (CS1-US). Yet, the differential startle fear response to the reactivated CS1 (trial 3) at the end of reacquisition demonstrates that the reconsolidation blockade does not interfere with the ability to subsequently reacquire fear responses (CS1 vs. CS3; $t_{(14)}=3.05, P<0.01$, two-tailed; CS1 vs. $\left.\mathrm{CS} 2 ; t_{(14)}<1.11\right)$.

The recovered fear response to the nonreactivated CS2 remained stable from the last trial of reacquisition (CS2 vs. CS3) to the generalization cue (G-CS2 vs. G-CS3; stimulus $\times$ trial, $\left.F_{(1,14)}<1.33\right)$. However, a significant decrease of the startle response to the generalization cue (G-CS1) of the reactivated CS1 was found (G-CS1 vs. G-CS3; stimulus $\times$ trial, $F_{(1,14)}=8.46$, $P<0.05, \eta^{2}=0.38$ ) (Fig. 2A). Indeed, we observed a significant generalization of fear to the nonreactivated generalization cue G-CS2 (G-CS2 vs. G-CS3; $t_{(14)}=3.20, P<0.01$, two-tailed; G-CS1 vs. G-CS2; $t_{(14)}=-3.03, P<0.01$, two-tailed). Conversely, the generalization cue (G-CS1) of the reactivated CS1 did not uncover 
any fear response (G-CS1 vs. G-CS3; $t_{(14)}<1$ ), indicating that the category-related information was also selectively affected by the propranolol manipulation.

\section{Administration of the $\beta$-adrenergic receptor antagonist propranolol prior to memory reactivation leaves the skin conductance response intact}

Overall analysis of electrodermal responding showed no skin conductance conditioning on day $1\left(\mathrm{CS}^{+}\right.$vs. $\mathrm{CS}^{-}, \mathrm{CS}^{+}$vs. $\mathrm{CS}^{-}$; stimulus $\times$trial, $\left.F_{(1,14)}<2.84\right)$. When skin conductance responses are not successfully acquired, one cannot assess the return of electrodermal activity. Therefore, only subjects showing successful levels of skin conductance conditioning (i.e., trial 5 $\mathrm{CS}^{+}$or $\mathrm{CS}^{+}>\mathrm{CS}^{-}$) were included in the analyses. Three subjects were eliminated.

Subsequent analysis of variance revealed a significant increase $\left(\mathrm{CS}^{+}\right.$vs. $\mathrm{CS}^{-}, \mathrm{CS}^{+}$vs. $\left.\mathrm{CS}^{-}\right)$in electrodermal activity during acquisition (day 1) (trial 1 vs. trial 5; stimulus $\times$ trial, $F_{(1,11)}=8.19, P<0.05, \eta^{2}=0.43 ; F_{(1,11)}=6.38, P<0.05, \eta^{2}=$ 0.37 , respectively) (Fig. $2 \mathrm{~B})$. We observed no difference in responding to the first trial of acquisition learning $\left(\mathrm{CS}^{+}\right.$vs. $\mathrm{CS}^{+}$vs. $\mathrm{CS}^{-}$) (stimulus, $F_{(2,10)}<1$ ). In line with our previous findings (Soeter and Kindt 2010), the administration of propranolol did not affect the skin conductance response to the reactivated CS1 from the last trial of acquisition to the first extinction trial 48 h later (day 3) (CS1 vs. CS3, CS2 vs. CS3; stimulus $\times$ trial, $\left.F_{(1,11)}<1\right)$. Further comparisons indeed showed intact electrodermal responding to both the reactivated CS1 and nonreactivated CS2 (CS1 vs. CS2; stimulus $\times$ trial, $F_{(1,11)}<1$ ). Moreover, a significant decrease in electrodermal responding (CS1 vs. CS3, CS2 vs. CS3) was observed during extinction learning (day 3) (trial 1 vs. trial 10; stimulus $\times$ trial, $F_{(1,11)}=5.32, P<0.05, \eta^{2}=0.33 ; F_{(1,11)}=$ 7.08, $P<0.05, \eta^{2}=0.39$, respectively).

Analysis of the reinstatement effect showed no differential increase (CS1 vs. CS3, CS2 vs. CS3) in electrodermal activity from the last trial of extinction to the first trial at test (stimulus $x$ trial, $F_{(1,11)}<1.52$ ) (Fig. $\left.2 \mathrm{~B}\right)$. However, for both the conditioned stimuli (CS1 and CS2) and the control stimulus (CS3) electrodermal responding increased following the reminders shocks (main effect of trial, $\left.F_{(1,11)}=6.33, P<0.05, \eta^{2}=0.37\right)$, demonstrating a generalization of the previously acquired skin conductance response to the control stimulus (Dirikx et al. 2007; Soeter and Kindt 2010). Further analyses of the reinstatement effect, therefore, only comprised skin conductance responses to the conditioned CS1 and CS2. Reanalyzing the reinstatement effect produced a significant return of electrodermal responding (CS1 vs. CS2; main effect of trial, $F_{(1,11)}=7.76, P<0.05, \eta^{2}=$ 0.41 ; stimulus $\times$ trial, $\left.F_{(1,11)}<1\right)$. Skin conductance responses again re-extinguished over the course of reinstatement testing (trial 1 vs. trial 5; main effect of trial, $F_{(1,11)}=7.09, P<0.05$, $\left.\eta^{2}=0.39\right)$.

Reacquisition learning did not result in a significant increase (CS1 vs. CS3, CS2 vs. CS3) (Fig. 2B) in electrodermal activity (trial 1 vs. trial 2 or trial 3; stimulus $\times$ trial, $\left.F_{(1,11)}<1.93\right)$. Notably, the differential skin conductance response (CS1 vs. CS3, CS2 vs. CS3) no longer reached significance (trial 2 and trial $3 ; t_{(11)}<1.31$ ). However, during generalization, a differential skin conductance response for both conditioned stimuli (G-CS1 vs. G-CS3, G-CS2 vs. G-CS3) was observed (main effect of stimulus, $F_{(1,11)}=7.42$, $P<0.05, \eta^{2}=0.40 ; F_{(1,11)}=8.13, P<0.05, \eta^{2}=0.43$, respectively), indicating that the electrodermal responding obtained during acquisition (day 1, trial 5) generalized to the categoryrelated cues (stimulus $\times$ trial, $F_{(1,11)}<1$ ).

In line with the skin conductance response data, we did not observe any effects of $\beta$-adrenergic receptor blockade during memory reactivation on the subjective distress ratings
(Supplemental Fig. 2) and retrospective US expectancy (Supplemental Fig. 3). See Supplemental Results for full analyses.

\section{Experiment $\mathrm{I}^{\mathrm{b}}$, Acquisition-Generalization}

\section{Relearning following the disruption of reconsolidation differs from initial learning}

Even though in Experiment I the startle fear response to the reactivated CS1 had recovered at the end of reacquisition, the fearerasing effects generalized to the category-related information. Several explanations can be offered for this lack of fear generalization. First of all, the strength of the memory trace following threetrial de novo fear acquisition may have been insufficient to trigger startle potentiation to cues that were category-related. Second, given the accumulating evidence that sleep facilitates the abstraction of general rules from existing information (Walker 2009), the immediate succession of testing phases may also explain the lack of a generalized fear response to the pharmacologically treated CS1. These two explanations predict a similar lack of fear generalization following initial three-trial fear acquisition. Alternatively, it may be possible that reconsolidation blockade not solely neutralizes the previously formed memory trace, but even suppresses synaptic plasticity. If reacquisition following reconsolidation blockade indeed differs mechanistically from initial learning, this might explain the lack of fear generalization for the pharmacologically treated CS1. Support for this alternative hypothesis would be provided when initial three-trial fear conditioning does elicit a generalized fear response. We conducted an additional experiment to explore these possibilities and recruited a new group of participants who were exposed to only three trials of acquisition learning (i.e., similar to the reacquisition procedure in Experiment I) directly followed by a test of fear generalization.

Analysis of variance revealed a significant differential increase of the startle fear response $\left(\mathrm{CS}^{+}\right.$vs. $\mathrm{CS}^{-}, \mathrm{CS}^{+}$vs. $\mathrm{CS}^{-}$) from trial 1 to trial 3 (stimulus $\times$ trial, $F_{(1,9)}=8.72, P<$ $0.05, \eta^{2}=0.49 ; F_{(1,9)}=21.90, P<0.001, \eta^{2}=0.71$, respectively). We observed no difference in responding to the first trial of acquisition $\left(\mathrm{CS}^{+}\right.$vs. $\mathrm{CS}^{+}$vs. $\left.\mathrm{CS}^{-}\right)$(stimulus, $F_{(2,8)}<1$ ) and fear responses to the reinforced stimuli $\left(\mathrm{CS}^{+}\right.$and $\left.\mathrm{CS} 2^{+}\right)$were equally acquired (stimulus $\times$ trial, $F_{(1,9)}<1$ ) (Fig. 3). The differential increase in startle fear responding remained stable from the last trial of acquisition to generalization (G-CS1 vs. G-CS3, G-CS2 vs. G-CS3; stimulus $\times$ trial, $\left.F_{(1,9)}<1\right)$. Indeed, we observed a significant generalization of fear to the G-CS1, as well as G-CS2 category-related cue (G-CS1 vs. G-CS3; $t_{(9)}=2.47, P<0.05$, two-tailed; G-CS2 vs. G-CS3; $t_{(9)}=3.35, P<0.01$, two-tailed;

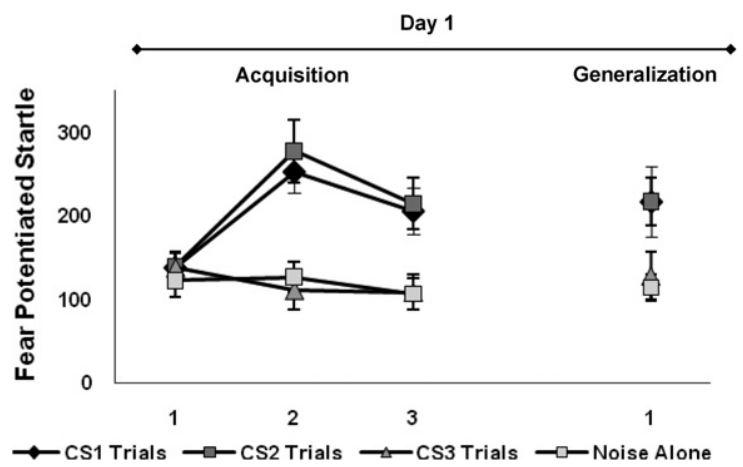

Figure 3. Experiment $\mathrm{I}^{\mathrm{b}}$, Acquisition-Generalization. Mean startle potentiation to the fear conditioned stimuli (CS1 and CS2), the control stimulus (CS3), and noise alone (NA) trials during acquisition and generalization. Error bars represent SEM. 
G-CS1 vs. G-CS2; $t_{(9)}<1$ ) (Fig. 3). Analysis of the skin conductance response, subjective distress ratings and retrospective US expectancy also revealed a generalization in responding to the category-related information. See Supplemental Figure 4 and Supplemental Results for full analyses. Together, these data indicate that the relearning of fear following the propranolol-induced amnesia differs mechanistically and qualitatively from initial fear acquisition.

\section{Experiment II, Reactivation-Extinction}

Reactivation of a memory prior to extinction learning prevents the spontaneous recovery of the startle response but does not "rewrite" the original fear association

Analysis of variance showed fear learning on day 1 by a significant differential increase of the startle fear response (i.e., simple contrasts: $\mathrm{CS}^{+}$vs. $\mathrm{CS}^{-}, \mathrm{CS}^{+}$vs. $\mathrm{CS}^{-}$) from trial 1 to trial 5 (stimulus $\times$ trial, $\quad F_{(1,13)}=11.75, \quad P<0.01, \quad \eta^{2}=0.48 ; \quad F_{(1,13)}=$ $6.27, P<0.05, \eta^{2}=0.33$, respectively). We observed no difference in responding to the first trial of acquisition $\left(\mathrm{CS}^{+}{ }^{+} \mathrm{vs}\right.$. $\mathrm{CS} 2^{+}$vs. $\mathrm{CS}^{-}{ }^{-}$) (stimulus, $F_{(2,13)}<1$ ) and fear responses to the reinforced $\mathrm{CS}^{+}$and $\mathrm{CS}^{+}$were equally acquired (stimulus $\times$trial, $F_{(1,13)}<1$ ) (Fig. 4A).

The startle fear response obtained during acquisition remained stable $24 \mathrm{~h}$ later, that is, from the last trial of acquisition to memory reactivation (CS1 vs. NA; stimulus $\times$ trial, $F_{(1,14)}<1$ ), as well as to the first extinction trial following reactivation of the memory (CS1 vs. CS3, CS2 vs. CS3; stimulus $\times$ trial, $F_{(1,13)}<$ 1 ). We observed a significant reduction of the differential startle fear response (CS1 vs. CS3, CS2 vs. CS3) from the first trial of extinction to the last trial of extinction learning (day 2) (stimulus $\times$ trial, $\quad F_{(1,14)}=11.53, \quad P<0.01, \quad \eta^{2}=0.48 ; \quad F_{(1,14)}=$ $5.51, P<0.05, \eta^{2}=0.28$, respectively) (Fig. 4 A) and fear responses to the reactivated CS1 and the nonreactivated CS2 were equally diminished (stimulus $\times$ trial, $F_{(1,14)}<1$ ). Moreover, the absence of a differential startle response on the last trial of extinction learning (CS1 vs. CS3, CS2 vs. CS3; $t_{(14)}<1.27$ ) demonstrates that the previously acquired fear was successfully extinguished (day 2).

Whereas the differential startle response to the nonreactivated CS2 recovered from the last extinction trial (day 2) to the first trial of re-extinction learning (day 3) (CS2 vs. CS3; stimulus $\times$ trial, $\left.F_{(1,14)}=12.39, P<0.01, \eta^{2}=0.47\right)$, the fear response to the reactivated CS1 remained eliminated $24 \mathrm{~h}$ later (CS1 vs. CS3; stimulus $\times$ trial, $\left.F_{(1,14)}<1\right)$. Indeed, we observed a significant return of fear to the nonreactivated CS2 as opposed to the reactivated CS1 stimulus (stimulus $\times$ trial, $F_{(1,14)}=10.14, P<0.01$, $\eta^{2}=0.42$ ) (Fig. 4A). The differential startle response to the reactivated CS1 even no longer reached significance on the first trial of re-extinction (day 3) (CS1 vs. CS3; $t_{(14)}<1$ ), indicating that retrieval of the fear memory (CS1-US) prior to extinction learning (day 2) selectively prevented the spontaneous recovery of fear $24 \mathrm{~h}$ later (day 3) (Schiller et al. 2010).

Consequently, a significant decrease of the differential startle response to the reactivated CS1 was observed from the last trial of acquisition (day 1 ) to the first re-extinction trial $48 \mathrm{~h}$ later (day 3 ) (CS1 vs. CS3; stimulus $\times$ trial, $\left.F_{(1,13)}=5.25, P<0.05, \eta^{2}=0.29\right)$ (Fig. 4A), irrespective of the reactivated stimulus (spider vs. gun; stimulus $\times$ trial $\times$ stimulus category, $\left.F_{(1,13)}<1.76\right)$. Conversely, startle responses to the nonreactivated CS2 remained stable from the last acquisition trial to the first trial of re-extinction learning (day 3) (CS2 vs. CS3; stimulus $\times$ trial, $\left.F_{(1,13)}<1\right)$. Further comparisons between the two feared stimuli indeed showed intact

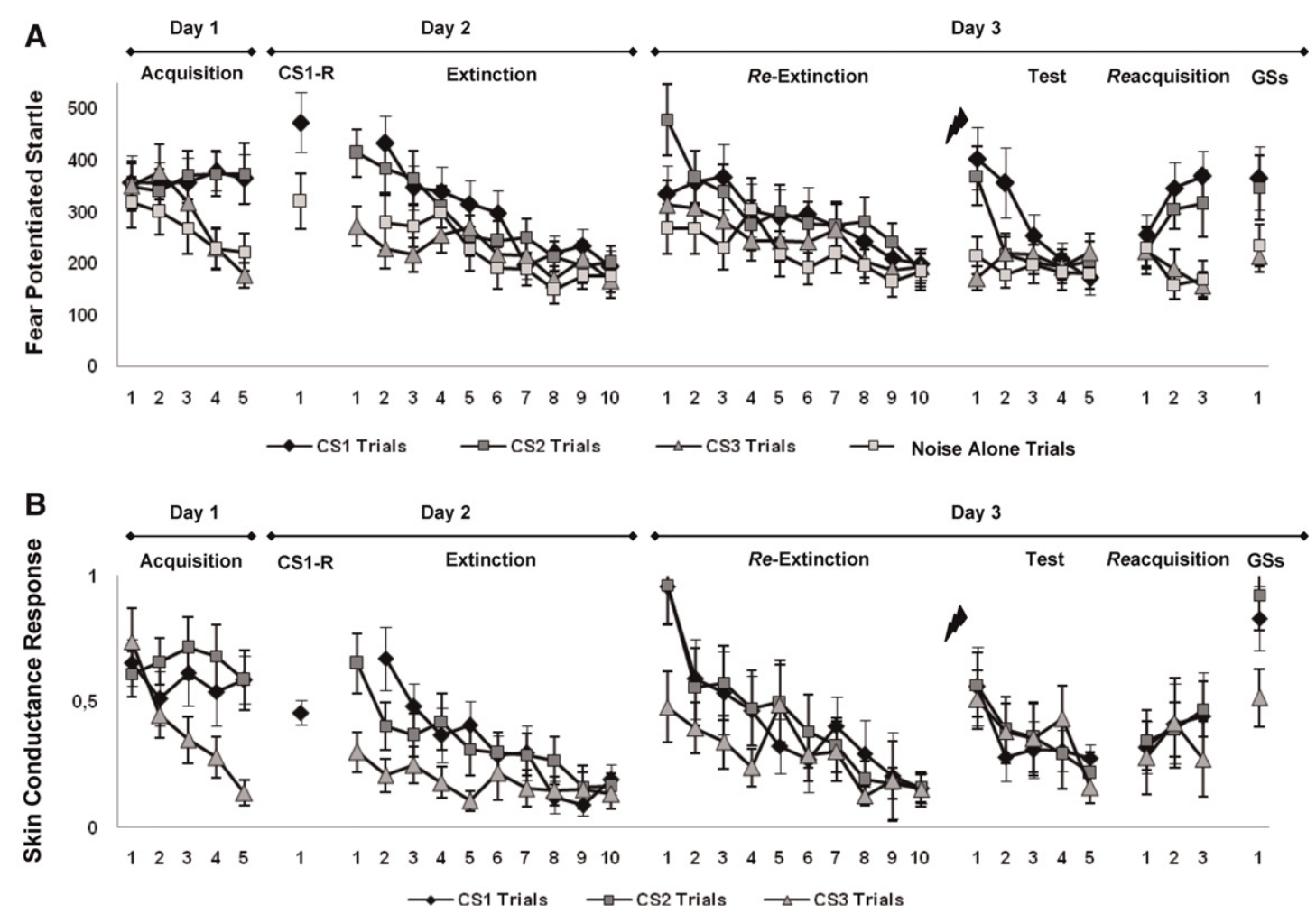

Figure 4. Experiment II, Reactivation-Extinction. (A) Mean startle potentiation to the fear conditioned stimuli (CS1 and CS2), the control stimulus (CS3), and noise alone (NA) trials during acquisition, memory reactivation, extinction, re-extinction, retest, reacquisition, and generalization. (B) Contrary to the findings of Schiller et al. (2010), we observed no effects of fear memory reactivation (CS1) prior to extinction learning on skin conductance conditioning. Error bars represent SEM. 
fear responses to the nonreactivated CS2 contrary to the reactivated CS1 (stimulus $\times$ trial, $F_{(1,13)}=4.47, P=0.054, \eta^{2}=0.26$ ).

Given that responses to the reactivated CS1 were already diminished (day 3), we observed no differential change in startle responses (CS1 vs. CS3) over the course of re-extinction learning (trial 1 vs. trial 10; stimulus $\times$ trial, $F_{(1,14)}<1$ ) (Fig. 4A). In contrast, startle responses to the nonreactivated CS2 significantly decreased from the first re-extinction trial to the last trial of re-extinction (CS2 vs. CS3; stimulus $\times$ trial, $F_{(1,14)}=16.75, P=$ $\left.0.001, \eta^{2}=0.55\right)$.

Although the spontaneous recovery of fear (day 3) (CS1 vs. CS3) was selectively prevented by reactivating the CS1 memory prior to extinction learning, the reminder shocks elicited a significant return of fear to the reactivated CS1 (CS1 vs. CS3; stimulus $x$ trial, $\left.F_{(1,14)}<19.88, P=0.001, \eta^{2}=0.59\right)$ as well as to the nonreactivated CS2 (CS2 vs. CS3; stimulus $\times$ trial, $F_{(1,14)}=18.85$, $\left.P=0.001, \eta^{2}=0.57\right)$. As we also observed no difference in the reinstatement of the fear response between the two conditioned stimuli (CS1 vs. CS2) (stimulus $\times$ trial, $F_{(1,14)}<1$ ) (Fig. $4 \mathrm{~A}$ ), these data demonstrate that the original fear association of the CS1 stimulus (i.e., CS1-US) remained intact. Re-extinction learning (trial 1 vs. trial 5) following the reminder shocks again reduced fear responses to both the reactivated CS1 (CS1 vs. CS3; stimulus $\times$ trial, $\left.F_{(1,14)}=19.02, P=0.001, \eta^{2}=0.61\right)$ and the nonreactivated CS2 (CS2 vs. CS3; stimulus $\times$ trial, $F_{(1,14)}=$ 12.56, $\left.P<0.01, \eta^{2}=0.51\right)$.

During reacquisition we observed a rapid recovery of the startle fear response (trial 1 vs. trial 2) to the reactivated CS1 (CS1 vs. CS3; stimulus $\times$ trial, $F_{(1,14)}=6.32, P<0.05, \eta^{2}=0.31$ ), as well as to the nonreactivated CS2 (CS2 vs. CS3; stimulus $\times$ trial, $F_{(1,14)}=$ 6.92, $P<0.05, \eta^{2}=0.33$ ). Further comparisons between the two feared stimuli revealed no differences in the return of fear during reacquisition (CS1 vs. CS2) (trial 1 vs. trial 2) (stimulus $\times$ trial, $F_{(1,14)}<1$ ) (Fig. 4A). Moreover, a significant differential fear response was observed at the end of reacquisition learning (trial 3) (CS1 vs. CS3; $t_{(14)}=6.07, P=0.001$, two-tailed; CS2 vs. CS3; $t_{(14)}=2.92, P<0.05$, two-tailed; CS1 vs. CS2; $\left.t_{(14)}<1.36\right)$.

The recovered fear response to both feared stimuli remained stable from the last trial of reacquisition (CS1 vs. CS3; CS2 vs. CS3) to the generalization cue (G-CS1 vs. G-CS3; stimulus $\times$ trial, $F_{(1,14)}<1$; G-CS2 vs. G-CS3; stimulus $\times$ trial, $\left.F_{(1,14)}<1\right)$ (Fig. $4 \mathrm{~A}$ ). Indeed, we observed a significant generalization of fear to the reactivated, as well as to the nonreactivated generalization cue (G-CS1 vs. G-CS3; $t_{(14)}=4.04, P=0.001$, two-tailed; G-CS2 vs. G-CS3; $t_{(14)}=3.16, P<0.01$, two-tailed) and no difference in fear generalization was observed between the two category-related cues (G-CS1 vs. G-CS2; $t_{(14)}<1$ ).

\section{Fear memory reactivation prior to extinction learning leaves the skin} conductance response untouched

Overall analysis of electrodermal responding showed no acquisition on day $1\left(\mathrm{CS}^{+}\right.$vs. $\mathrm{CS}^{-}, \mathrm{CS}^{+}$vs. $\mathrm{CS}^{-}$; stimulus $\times$trial, $\left.F_{(1,14)}<2.86\right)$. Therefore, only subjects showing successful levels of skin conductance conditioning (i.e., trial $5 \mathrm{CS}^{+}$or $\mathrm{CS} 2^{+}>$ $\mathrm{CS}^{-}$) were included in the analyses (see Experiment I, Propranolol-Reactivation). Two subjects were eliminated.

Subsequent analysis of variance revealed a significant differential increase in electrodermal activity $\left(\mathrm{CS}^{+}{ }^{+}\right.$vs. $\mathrm{CS}^{-}, \mathrm{CS}^{+}$vs. $\mathrm{CS}^{-}$) from trial 1 to trial 5 (day 1 ) (stimulus $\times$ trial, $F_{(1,12)}=8.10$, $P<0.05, \eta^{2}=0.40 ; F_{(1,12)}=5.43, P<0.05, \eta^{2}=0.31$, respectively) (Fig. 4B). We observed no difference in responding to the first trial of acquisition learning $\left(\mathrm{CS}^{+}{ }^{+} \mathrm{vs}\right.$. $\mathrm{CS} 2^{+}$vs. $\mathrm{CS}^{-}$) (stimulus, $\left.F_{(2,11)}<1\right)$. The differential increase in electrodermal activity (CS1 vs. CS3, CS2 vs. CS3, CS1 vs. CS2) obtained during acquisition (trial 5) remained stable $24 \mathrm{~h}$ later (extinction trial 1; stimulus $\times$ trial $\left.F_{(1,12)}<1\right)$. Moreover, we observed a significant decrease in electrodermal responding (CS1 vs. CS3, CS2 vs. CS3) during extinction learning (day 2) (trial 1 vs. trial 10; stimulus $\times$ trial, $F_{(1,12)}=5.04, P<0.05, \eta^{2}=0.30 ; F_{(1,12)}=5.30, P<0.05$, $\eta^{2}=0.31$, respectively).

Contrary to the findings by Schiller et al. (2010), skin conductance responses to both the reactivated CS1 (CS1 vs. CS3; stimulus $\times$ trial, $\left.F_{(1,12)}=7.22, P<0.05, \eta^{2}=0.38\right)$ and the nonreactivated CS2 (CS2 vs. CS3; stimulus $\times$ trial, $F_{(1,12)}=8.89, P<$ $0.05, \eta^{2}=0.43$ ) (Fig. $4 \mathrm{~B}$ ) recovered from the last extinction trial (day 2) to the first trial of re-extinction learning (day 3). Further comparisons indeed showed no difference in the return of electrodermal responding between the two conditioned stimuli (CS1 vs. CS2; stimulus $\times$ trial, $\left.F_{(1,12)}<1\right)$. We again observed a significant decrease in electrodermal activity (CS1 vs. CS3, CS2 vs. CS3) during re-extinction learning (day 3) (trial 1 vs. trial 10; stimulus $\times$ trial, $F_{(1,12)}=4.90, P<0.05, \eta^{2}=0.29 ; F_{(1,12)}=5.09, P<0.05$, $\eta^{2}=0.30$, respectively).

Analysis of the reinstatement effect revealed no differential increase (CS1 vs. CS3, CS2 vs. CS3) in electrodermal responding from the last re-extinction trial to the first trial at test (stimulus $\times$ trial, $\left.F_{(1,12)}<1\right)$. However, for both the conditioned CSs (CS1 and CS2) and the control stimulus (CS3) we observed an increase in electrodermal activity following the reminder shocks (main effect of trial, $F_{(1,12)}=18.15, P=0.001, \eta^{2}=0.60$ ) (Fig. 4B). Therefore, further analyses of the reinstatement effect only comprised skin conductance responses to the conditioned stimuli (CS1 and CS2). Reanalyzing the reinstatement effect produced a significant return of electrodermal activity (CS1 vs. CS2; main effect of trial, $F_{(1,12)}=18.68, P=0.001, \eta^{2}=0.61$; stimulus $\times$ trial, $\left.F_{(1,12)}<1\right)$. Skin conductance responses again re-extinguished over the course of reinstatement testing (trial 1 vs. trial 5; main effect of trial, $\left.F_{(1,12)}=14.81, P<0.01, \eta^{2}=0.55\right)$.

Reacquisition learning did not result in a significant increase (CS1 vs. CS3, CS2 vs. CS3) in electrodermal responding (trial 1 vs. trial 2 or trial 3; stimulus $\times$ trial, $\left.F_{(1,12)}<1.12\right)$. The differential skin conductance response (CS1 vs. CS3, CS2 vs. CS3) even no longer reached significance (trial 2 and trial $3 ; t_{(12)}<1.46$ ). However, a differential skin conductance response for both conditioned stimuli (G-CS1 vs. G-CS3, G-CS2 vs. G-CS3) was observed during generalization (main effect of stimulus, $F_{(1,12)}=4.87, P<0.05$, $\eta^{2}=0.28 ; \quad F_{(1,12)}=5.30, \quad P<0.05, \quad \eta^{2}=0.31, \quad$ respectively) (Fig. 4B), indicating that the skin conductance response obtained during acquisition (CS1 vs. CS3, CS2 vs. CS3) (day 1, trial 5) generalized to the category-related information (trial 1) (G-CS1 vs. G-CS3, G-CS2 vs. G-CS3; stimulus $\times$ trial, $\left.F_{(1,12)}<1\right)$.

Similar to the skin conductance response data, we did not observe any effect of fear memory reactivation (CS1) prior to extinction learning on subjective distress (Supplemental Fig. 5) and retrospective US expectancy (Supplemental Fig. 6). See Supplemental Results for full analyses.

\section{Discussion}

Here, we demonstrate that $\beta$-adrenergic receptor blockade during memory reconsolidation resulted in selective erasure of the startle fear response to both the reactivated fear association and its category-related information. Even though administering pills prior to reactivation does not discard the effect of the drug on memory retrieval itself rather than on reconsolidation, the fearreducing effects were only observed during the post-reactivation tests. The intact startle potentiation during memory reactivation further suggests that a nonspecific dampening effect of the $\beta$-adrenergic receptor antagonist cannot explain the erasure of the startle fear response. It is also noteworthy that we recently observed a similar reduction in startle fear responding when 
propranolol was administered after reactivation of the memory (M Soeter and M Kindt, in prep.). In line with our previous studies (Kindt et al. 2009; Soeter and Kindt 2010), the propranolol manipulation left the declarative aspects of the fear memory intact (i.e., skin conductance conditioning, subjective distress and expectancy ratings), signifying no updating of the more cognitive and conscious memory representation (Lee 2009). Importantly though, the administration of the $\beta$-adrenergic receptor antagonist selectively "deleted" the fear-arousing aspects of the reactivated memory, as reacquisition learning did not reveal any savings of the fear response. This contrasts sharply with the rapid reacquisition of the fear response to the nonreactivated cue, demonstrating that extinction learning leaves the original fear memory intact (Bouton 2002). The fear-erasing effects following reconsolidation blockade were not restricted to the reactivated fear association, but instead generalized to cues that were category-related (i.e., fear network), even though the fear response to the updated cue had recovered at the end of reacquisition. Relearning following the disruption of reconsolidation seems to be qualitatively different from original learning given that threetrial fear acquisition in naive participants was sufficient to produce a generalized fear response (Experiment $\mathrm{I}^{\mathrm{b}}$ ). The generalization of fear has been demonstrated to be dependent on the strength of the memory as operationalized by training intensity (Laxmi et al. 2003). Apparently, $\beta$-adrenergic interference with reconsolidation rendered the core memory trace too weak for fear generalization to occur following successful reacquisition. The propranolol manipulation may have suppressed the synaptic plasticity instead of solely neutralizing the emotional impact of the memory. Among other noradrenergic receptor antagonists, propranolol has been shown to inhibit noradrenaline-stimulated CREB phosphorylation by blocking the classical $\beta$-adrenergic/ cAMP pathway (Jockers et al. 1998; Chaundhry and Granneman 1999; Thonberg et al. 2002). CREB has not only been implicated in the formation but also in the generalization of associative fear memory (Han et al. 2008). Our findings further demonstrate that the assimilation of individual memory items into a generalized schema may be dissociable for semantic and affective knowledge. That is, upon exposure to the cues that were category-related to the reactivated fear association, the participants again predicted danger without a concomitant fear response (Fig. 2; Supplemental Figs. 2, 3).

Contrary to the findings by Schiller et al. (2010), we did not observe any effects of the behavioral procedure presented within the reconsolidation window on skin conductance discrimination. These data do not lend support for interference with the process of reconsolidation given that the informational value (i.e., extinction learning) provided during retrieval should at least have allowed for updating at the more cognitive level of memory. There are a number of procedural differences that may account for the discrepancy between findings. First of all, being especially resistant to extinction learning (Mineka and Öhman 2002), the fear-relevant stimuli (as opposed to geometric figures) may have rendered the procedure ineffective. Although extinction learning subsequent to memory retrieval successfully eliminated the previously acquired skin conductance response, this does not prove that the number of extinction trials was sufficient for updating the original fear memory. Given that anxiety disorders do not tend to be associated with fear-irrelevant stimuli (e.g., geometric figures), but rather with objects and situations related to survival threats (i.e., fear-relevant stimuli) (Mineka and Öhman 2002), a behavioral procedure should also be suitable for updating stronger fear memory. Second, the ratings of subjective distress or the presentation of the startle probe may have interfered with the measurement of electrodermal activity. On the other hand, we observed a clear conditioning for the skin conductance response during fear acquisition, refuting the idea that the acoustic stimulus disrupted the electrodermal activity. Moreover, we recently observed that omitting "online ratings" does not differentially affect skin conductance responding (M Soeter and $\mathrm{M}$ Kindt, in prep.). Further, note that we also did not observe any effects on the other measures of declarative memory (i.e., distress ratings, expectancy ratings). Even though the retrieval trial prior to extinction learning selectively prevented the spontaneous recovery of the startle fear response, the reminder shocks and reacquisition learning both resulted in the return of fear responding. Thus, the spacing of the single trial during memory retrieval relative to extinction learning did not allow for "rewriting" the original fear association, but instead yielded a more persistent extinction performance, restricted to the startle fear response. Like reconsolidation, extinction learning also enables memories to be updated or modified (Lee 2009). For both approaches, retrieval renders the memory vulnerable for modification by returning it to a plastic state. The $10 \mathrm{~min}$ between the first extinction trial (i.e., memory retrieval) and the other extinction trials apparently induced more plasticity of the fear memory such that a stronger inhibitory memory trace could be formed.

Overall, the present findings stand in sharp contrast to those reported by Schiller et al. (2010). It is important to note that Schiller et al. (2010) disregarded the first test trial in demonstrating the persistent alteration of the fear memory one year later. This trial is essential in determining the return of fear; the more so as the first test trial itself traditionally results in extinction learning. Albeit animal studies showed fear-erasing effects by the behavioral disruption of reconsolidation, that is, when presented shortly after initial consolidation (Monfils et al. 2009; Clem and Huganir 2010), subtle procedural variations (i.e., context change) also produced contrasting results in a recent study in rats (Chan et al. 2010). Among the above-mentioned procedural differences (e.g., fear-relevant stimuli), our study diverged from that of Schiller et al. (2010) in a reinforcement scheme during fear acquisition (i.e., $80 \%$ vs. 38\% reinforcement scheme, respectively). The retrieval trial in our study may therefore have triggered extinction learning instead of reconsolidation of the memory (Pedreira et al. 2004). This is, however, difficult to reconcile with our pharmacological data. The issue of whether a new experience updates an existing memory (i.e., reconsolidation) or triggers a new memory formation (i.e., extinction) might depend on the duration of the reactivation (Suzuki et al. 2004). Prolonged re-exposure (i.e., extinction) may prevent reconsolidation from occurring (Lee et al. 2006). Although the re-exposure to the conditioned stimulus was similar for the pharmacological and behavioral manipulation, its relation to initial learning may govern the interaction between reconsolidation and extinction. The experimental parameters determining whether extinction or reconsolidation predominates may differ between pharmacological and behavioral manipulations.

In sum, the behavioral procedure (i.e., extinction learning) did not allow for updating of either the emotional expression or the cognitive representation of a strong fear memory. In contrast, the disruption of reconsolidation by the pharmacological manipulation selectively "neutralized" the fear-arousing aspects of the memory along with its category-related information. Given that the generalization of fear lies at the heart of many anxiety disorders, these findings may have important therapeutic implications.

\section{Materials and Methods}

\section{Subjects}

Forty undergraduate students (11 men, 29 women) from the University of Amsterdam ranging in age from 18 to $32 \mathrm{yr}$ 
(mean \pm SD age, $21.8 \pm 3.1 \mathrm{yr}$ ) participated in the study. All participants were assessed to be free from any current or previous medical or psychiatric condition that would contraindicate participation (i.e., pregnancy; seizure disorder; respiratory disorder; cardiovascular disease; blood pressure $\leq 90 / 60$; diabetes; liver kidney disorder; previous adverse reaction to a $\beta$-blocker; use of another $\beta$-blocker; use of medication that could involve potentially dangerous interactions with propranolol; depression; or psychosis). An additional exclusion criterion contained a score $\geq 26$ on the Anxiety Sensitivity Index (ASI) (Peterson and Reiss 1992). Participants received either partial course credits or were paid a small amount for their participation in one of the experiments. The study was approved by the ethical committee of the University of Amsterdam and informed consent was obtained from all participants.

\section{Apparatus and materials}

\section{Stimuli}

In order to strengthen the fear association during acquisition, two fear-relevant stimuli of different stimulus categories served as $\mathrm{CS}^{+ \text {'s }}$ (i.e., spider-gun; IAPS numbers 1200-6210) (see Supplemental Fig. 1), whereas a fear-irrelevant stimulus served as $\mathrm{CS}^{-}$ (i.e., mug; IAPS number 7009) (Lang et al. 2005). The slides were $200 \mathrm{~mm}$ high and $270 \mathrm{~mm}$ wide and were presented in the middle of a black screen on a 19-in computer monitor. The two fearrelevant stimuli $\left(\mathrm{CS}^{+}\right.$and $\left.\mathrm{CS}^{+}\right)$were followed by a US, whereas the other slide $\left(\mathrm{CS}^{-}\right)$was not. Assignment of the slides as $\mathrm{CS} 1^{+}$ and $\mathrm{CS}^{+}$was counterbalanced across participants. Generalization stimuli (G-CS1 ${ }^{-}, \mathrm{G}-\mathrm{CS} 2^{-}$, and $\mathrm{G}-\mathrm{CS} 3^{-}$) were matched on stimulus category, valence, and arousal (IAPS numbers 12016200-7035) (see Supplemental Fig. 1). All stimuli were presented for $8 \mathrm{sec}$. The startle probe was presented $7 \mathrm{sec}$ after CS onset and was followed by the US (CS1 ${ }^{+}$and $\left.\mathrm{CS}^{+}\right) 500$ msec later. An electric stimulus with duration of $2 \mathrm{msec}$, delivered to the wrist of the nonpreferred hand, served as US. Delivery of the electric stimulus was controlled by a Digitimer DS7A constant current stimulator via a pair of Ag electrodes of $20 \times 25 \mathrm{~mm}$ with a fixed interelectrode mid-distance of $45 \mathrm{~mm}$. A conductive gel (Signa, Parker) was applied between the electrodes and the skin.

\section{Fear potentiated startle}

The conditioned fear response (CR) was measured as potentiation of the eyeblink startle reflex to a loud noise by electromyography (EMG) of the right orbicularis oculi muscle. Potentiation of the startle blink response is only observed during aversive fear conditioning (Weike et al. 2007). Neurally, it reflects the influence of direct and indirect connections from the amygdala to the primary startle-reflex pathway in the brainstem (Davis and Whalen 2001). The loud noise (40 msec; $104 \mathrm{~dB}$ ) was administered during each CS presentation and during intertrial intervals (NA: noise alone). Two 7-mm Ag/ $\mathrm{AgCl}$ electrodes filled with electrolyte gel were positioned $\sim 1 \mathrm{~cm}$ under the pupil and $1 \mathrm{~cm}$ below the lateral canthus; a ground reference was placed on the forehead. All acoustic stimuli were delivered binaurally through headphones (Model MD-4600; Compact Disc Digital Audio, Monacor). The eyeblink EMG activity was measured using a bundled pair of electrode wires connected to a front-end amplifier with an input resistance of 10 $\mathrm{M} \Omega$ and a bandwidth of DC- $1500 \mathrm{~Hz}$. To remove unwanted interference, a notch filter was set at $50 \mathrm{~Hz}$. Integration was handled by a true-RMS converter (contour follower) with a time constant of $25 \mathrm{msec}$. The integrated EMG signal was sampled at $1000 \mathrm{~Hz}$. Peak amplitudes were identified over the period of 50-100 msec following probe onset.

\section{Skin conductance response}

Electrodermal activity (SCR) was measured using an input device with a sine-shaped excitation voltage $( \pm 0.5 \mathrm{~V})$ of $50 \mathrm{~Hz}$, derived from the main frequency. The input device was connected to two $\mathrm{Ag} / \mathrm{AgCl}$ electrodes of $20 \times 16 \mathrm{~mm}$. The electrodes were attached to the medial phalanges of the first and third fingers of the nonpreferred hand. The signal from the input device was led through a signal-conditioning amplifier and the analog output was digitized at $100 \mathrm{~Hz}$ by a 16-bit AD-converter (National Instruments, NI-6224). Skin conductance responses elicited by the CS were determined by taking the average baseline (i.e., 2 sec before CS onset) to peak difference within the 1-7 sec window following stimulus onset. Although many studies examining skin conductance reactivity have either used the first interval response (FIR) or second interval response (SIR), the present scoring method allowed for the detection of the maximal increase in skin conductance levels at any point during the 7-sec presentation. This method makes no assumptions about where a response is likely to occur within the CS-US interval. This eliminates the risk of underestimating a larger response when the onset or peak of the response occurs near a previously established boundary between the FIR and SIR or when the latency of the peak response shifts over trials (Pineles et al. 2009). This approach has been used in previous human psychophysiological research, which has supported its validity (e.g., Orr et al. 2000; Milad et al. 2005; Pineles et al. 2009).

A minimum response criterion of 0.02 micro-Siemens $(\mu S)$ was used. All other responses were scored as zero and remained in the analyses (Effting and Kindt 2007). The raw SCR scores were square-root transformed to normalize distributions.

\section{Distress ratings}

Subjective distress (i.e., anxiety, tension, or nervousness) during CS presentation was measured online using a computer mouse on a visual analog scale placed within reach of the preferred hand. The scale consisted of a $100-\mathrm{mm}$ horizontal line with endpoints of 0 (i.e., "not at all") and 10 (i.e., "very"). The scale and the participant's rating were continuously presented at the bottom of the computer screen in order to encourage participants to focus their attention to the CSs. Participants were required to rate their distress during the presentation of each slide by shifting the cursor on the scale and push the left mouse button within 5 sec following stimulus onset, that is, before administration of the startle probe.

\section{Blood pressure}

Blood pressure was measured using an electronic sphygmomanometer (OMRON M4-I, Healthcare Europe BV) with a cuff applied around the right upper arm.

\section{Saliva sampling}

The salivary enzyme $\alpha$-amylase (sAA) is a reliable indicator of noradrenergic activation (Stegeren et al. 2006). Levels were assessed out of unstimulated saliva samples obtained using regular cotton Salivette sampling devices (Sarstedt) without chemical stimulants. Subjects were asked just to place the swab in their mouths for a 3-min period. After removal, the salivettes were stored at $-25^{\circ} \mathrm{C}$. To facilitate salivary sampling, participants were instructed to refrain from exercise, caffeine, and alcohol during the $12 \mathrm{~h}$ before each session. Also, they were instructed to abstain from brushing their teeth for $1 \mathrm{~h}$ and avoid food intake, drinking any beverages other than water, and smoking for $2 \mathrm{~h}$ before each session. Upon completion of the study, the samples were sent to Groningen for biochemical analysis (Universitair Medisch Centrum). See Supplemental Results for full analyses of the salivary $\alpha$-amylase.

\section{Pharmacological treatment}

Propranolol $\mathrm{HCl}(40 \mathrm{mg})$ and placebo pills were prepared by the pharmacy (Huygens Apotheek) to be identical in appearance.

\section{Subjective assessments}

State and trait anxiety were assessed with the State and Trait Anxiety Inventory (STAI-S and STAI-T) (Spielberger et al. 1970). 
The degree of spider fear was determined by the Spider Phobic Questionnaire (SPQ) (Klorman et al. 1974). The Anxiety Sensitivity Index (ASI) (Peterson and Reiss 1992) was used to assess one's tendency to respond fearfully to anxiety-related symptoms. Arousal and valence of the stimuli were assessed using the SelfAssessment Manikin (SAM) (Bradley and Lang 1994). Evaluation of the US was measured on an 11-point rating scale ranging from -5 (unpleasant) to 5 (pleasant). In addition, expectancy of the US was measured retrospectively on a continuous rating scale consisting of 11 points labeled from "certainly no electric stimulus" ( -5$)$ through "uncertain" (0) to "certainly an electric stimulus" (5).

\section{Experimental procedure}

Participants were subjected to a differential fear conditioning procedure including several phases across three subsequent days each separated by $24 \mathrm{~h}$ (i.e., Experiment I, Propranolol-Reactivation and Experiment II, Reactivation-Extinction). During each session, participants sat behind a table with a computer monitor at a distance of $50 \mathrm{~cm}$ in a sound-attenuated room. Each session began with a 1-min acclimation period consisting of 70-dB broadband noise, which continued throughout the session as background noise, followed by a habituation phase consisting of 10 startle probes to reduce initial startle reactivity. Characteristics of the CSs, trial order, ITIs, and startle probes, as well as instructions regarding distress ratings during memory reactivation(extinction) (day 2) and extinction-test (day 3) were similar to acquisition (day 1). Assignment of the slides as $\mathrm{CS}^{+}$and $\mathrm{CS} 2^{+}$ was counterbalanced across participants.

\section{Day 1: Acquisition}

Details of the various study procedures were explained in full and possible questions were answered. Participants were interviewed regarding their health and any medical or psychiatric conditions. In addition, blood pressure was measured. Once a participant was medically cleared, written informed consent was obtained and the ASI, SPQ, STAI, and SAM were administered. Further, saliva samples were collected. To this end, participants were instructed just to place the swab in their mouths for $3 \mathrm{~min}$.

After attachment of the startle, skin conductance and shock electrodes, the intensity of the US was determined. Starting at an intensity of $1 \mathrm{~mA}$, the level of a 2-msec aversive electric stimulus delivered to the wrist of the nonpreferred hand was gradually increased. The intensity of shock was individually set at a level defined by the participant as "uncomfortable, but not painful" and remained set to this intensity throughout the following days. After US selection, participants were informed regarding the CSs. They were instructed that two of the slides would be followed by an electric stimulus in most of the cases, whereas the third slide would never be followed by the US. They were told to learn to predict whether an electric stimulus would occur or not. In addition, participants were required to rate their distress (i.e., anxiety, tension, or nervousness) during the presentation of each slide by shifting a cursor on a visual analog scale and push the left mouse button within $5 \mathrm{sec}$ following stimulus onset, that is, before administration of the startle probe.

In the acquisition phase, the $\mathrm{CS}_{1}^{+}, \mathrm{CS}^{+}$, and $\mathrm{CS}^{-}$were presented five times for $8 \mathrm{sec}$. The startle probe was presented $7 \mathrm{sec}$ after CS onset and was followed by the US $500 \mathrm{msec}$ later. In order to prevent that the reactivation trial on day 2 resulted in extinction learning, the first presentation of both the $\mathrm{CS}^{+}$and $\mathrm{CS} 2^{+}$ was unreinforced (LaBar et al. 1998). In addition, five baseline startle probes were presented alone (noise alone; NA). The order of the trial type was randomized within blocks (i.e., $\mathrm{CS} 1^{+}, \mathrm{CS}^{+}$, $\mathrm{CS}^{-}$, and NA). Intertrial intervals (ITI) varied between 15,20 , and $25 \mathrm{sec}$ with a mean of $20 \mathrm{sec}$.

At the conclusion of the experiment, participants were asked to evaluate the pleasantness of the US and complete the STAI-S and SAM. Further, they were explicitly instructed to remember what they had learned during acquisition. These instructions were included to enhance retention of the CS-US contingency on the following days (Norrholm et al. 2006) and to prevent participants from erroneously expecting a different contingency scheme during subsequent testing.

The experimental procedure for Experiment $\mathrm{I}^{\mathrm{b}}$, AcquisitionGeneralization, paralleled the previous experiment except for stimulus presentation. That is, participants were exposed to three $\mathrm{CS}^{+}{ }^{+}, \mathrm{CS}^{+}, \mathrm{CS}^{-}$, and NA trials followed by the generalization cues (G-CS1 ${ }^{-}$, G-CS2 ${ }^{-}$, G-CS3 ${ }^{-}$, and NA).

\section{Day 2: Memory reactivation (extinction)}

In order to substantiate consolidation of the fear memory, a break of $24 \mathrm{~h}$ after acquisition was inserted. The STAI-S was filled out both before pill administration and upon completion of the experiment. In addition, at these time points, blood pressure and saliva samples were collected.

Experiment I, Propranolol-Reactivation: In view of the peak plasma concentration of propranolol (Gilman and Goodman 1996), all of the participants received single-blind an oral dose of $40 \mathrm{mg}$ of propranolol $90 \mathrm{~min}$ prior to memory reactivation (CS1-R). After electrode attachment, participants were told that the same three slides would be presented and they were asked to remember what they had learned during acquisition. Further instructions regarding the distress ratings were similar to day 1 . In the memory reactivation phase, a single unreinforced CS1-R was presented for $8 \mathrm{sec}$, followed by a startle probe presented alone.

Experiment II, Reactivation-Extinction: To match the conditions of Experiment I (i.e., pill administration, time spent at the experimental site), the participants received single-blind an oral dose of pill placebo $55 \mathrm{~min}$ prior to memory reactivation. For the reactivation procedure, see Experiment I, PropranololReactivation. Subsequent to memory reactivation, a 10-min break was inserted (Schiller et al. 2010). During the break, participants were offered magazines to read. Extinction learning immediately followed and consisted of $9 \mathrm{CS}^{-}, 10 \mathrm{CS}^{-}, 10 \mathrm{CS}^{-}$, and $10 \mathrm{NA}$ trials.

\section{Day 3: (Re)-extinction, testing}

Upon arriving at the experimental site, blood pressure and saliva samples were collected. In addition, the STAI-S and SAM were completed. Instructions regarding the CSs only revealed that the same three pictures provided during acquisition would be presented. In the (re)-extinction phase, participants were exposed to the $\mathrm{CS}^{-}$, $\mathrm{CS} 2{ }^{-}$, and $\mathrm{CS}^{-}$for 10 times without the US. Further, 10 startle probes were presented alone (NA). After extinction, participants received three unsignaled USs. The time between the last extinction trial and the reinstating USs was 19 sec. Following the unsignaled USs, participants were again presented with five $\mathrm{CS}^{-}, \mathrm{CS}^{-}, \mathrm{CS}^{-}$, and NA trials (reinstatement testing). The time between the reinstating USs and reinstatement testing was $18 \mathrm{sec}$. Next, reacquisition took place. That is, participants were exposed to another three $\mathrm{CS}^{+}, \mathrm{CS}^{+}, \mathrm{CS}^{-}$, and NA trials. Subsequently, they were presented with generalization cues (G-CS1 ${ }^{-}$, G-CS2 ${ }^{-}, \mathrm{G}_{-} \mathrm{CS}^{-}$, and NA). At the conclusion of the experiment, participants completed the STAI-S and SAM and judged the pleasantness of the US. In addition, participants were asked to indicate for each phase (beginning vs. end) of the experiment to what extent they had expected the US after each of the CSs.

\section{Statistical analysis}

Startle responses, electrodermal activity, distress, and US-expectancy ratings were analyzed by means of an analysis of variance (ANOVA) for repeated measures with stimulus (i.e., simple contrasts: CS1 vs. CS3 and CS2 vs. CS3) and trial (i.e., stimulus presentation) as within-subject factors. The differential response (CS1 vs. CS3 and CS2 vs. CS3) was compared over testing phases, respectively (first trial vs. last trial). Planned comparisons between CS1 and CS2 stimuli were performed separately. Missing data points were excluded from the analyses. Significance was taken at $P<0.05$. 


\section{Acknowledgments}

We thank B. Molenkamp for technical assistance. Furthermore, we are grateful for the comments and suggestions offered by the reviewers. This work was supported by a Vici grant (Merel Kindt) from The Netherlands Organization for Scientific Research.

\section{References}

Bouton ME. 2002. Context, ambiguity, and unlearning: Sources of relapse after behavioral extinction. Biol Psych 52: 976-986.

Bradley MM, Lang PJ. 1994. Measuring emotion: The self-assessment manikin and the semantic differential. J Behav Ther Exp Psych 25: 49-59.

Chan WYM, Leung HT, Westbrook F, McNally GP. 2010. Effects of recent exposure to a conditioned stimulus on extinction of Pavlovian fear conditioning. Learn Mem 17: 512-521.

Chaundhry A, Granneman JG. 1999. Differential regulation of function responses by $\beta$-adrenergic receptor subtypes in brown adipocytes. Am J Physiol 227: 137-153.

Clem RL, Huganir RL. 2010. Calcium-permeable AMPA receptor dynamics mediate fear memory erasure. Science 330: 1108-1112.

Davis M. 2006. Neural systems involved in fear and anxiety measured with fear potentiated startle. Am Psychol 61: 741-756.

Davis M, Whalen PJ. 2001. The amygdala: Vigilance and emotion. Mol Psychiatry 6: 13-34.

Dębiec J, LeDoux JE. 2004. Disruption of reconsolidation but not consolidation of auditory fear conditioning by noradrenergic blockade in the amygdala. Neurosci 129: 267-272.

Dębiec J, Doyère V, Nader K, LeDoux JE. 2006. Directly reactivated, but not indirectly reactivated, memories undergo reconsolidation in the amygdala. Proc Natl Acad Sci 103: 3428-3433.

Dirikx T, Hermans D, Vansteenwegen D, Baeyens F, Eelen P. 2007. Reinstatement of conditioned responses in human differential fear conditioning. J Behav Ther Exp Psych 38: 237-251.

Doyère V, Dębiec J, Monfils M-H, Schafe GE, LeDoux JE. 2007. Synapse-specific reconsolidation of distinct fear memories in the lateral amygdala. Nat Neurosci 10: 414-416.

Dudai Y. 2006. Reconsolidation: The advantage of being refocused. Curr Opin Neurobiol 16: 174-178.

Effting M, Kindt M. 2007. Contextual control of human fear associations in a renewal paradigm. Behav Res Ther 45: 2002-2018.

Gilman AG, Goodman LS. 1996. Goodman and Gilman's: The pharmacological basis of therapeutics. McGraw-Hill, New York.

Hamm AO, Weike AI. 2005. The neuropsychology of fear learning and fear regulation. Int J Psychophysiol 57: 5-14.

Han J-H, Yiu AP, Cole CJ, Hsiang H-L, Neve RL, Josselyn SA. 2008. Increasing CREB in the auditory thalamus enhances memory and generalization of auditory conditioned fear. Learn Mem 15: 443-453.

Jockers R, Issad T, Zilberfarb V, de Coppet P, Marullo S, Strosberg AD. 1998. Desensitization of the $\beta$-adrenergic response in human brown adipocytes. Endocrinology 139: 2676-2684.

Kindt M, Soeter M, Vervliet B. 2009. Beyond extinction: Erasing human fear responses and preventing the return of fear. Nat Neurosci 12: 256-258.

Klorman R, Weerts TC, Hastings JE, Melamed GBG, Lang PJ. 1974. Psychometric description of some specific fear questionnaires. Behav Ther 5: 401-409.

LaBar KS, Gatenby JC, Gore JC, LeDoux JE, Phelps EA. 1998. Human amygdala activation during conditioned fear acquisition and extinction: A mixed-trial fMRI study. Neuron 20: 937-945.

Lang PJ, Bradley MM, Cuthbert BM. 2005. International affective picture system (IAPS): Affective ratings of pictures and instruction manual. University of Florida, Gainesville, FL.

Laxmi TR, Stork O, Pape H-C. 2003. Generalisation of conditioned fear and its behavioural expression in mice. Behav Brain Res 145: 89-98.
Lee JLC. 2009. Reconsolidation: Maintaining memory relevance. Trends Neurosci 32: 413-420

Lee JLC, Milton AL, Everitt BJ. 2006. Reconsolidation and extinction of conditioned fear. I Neurosci 26: 10051-10056.

Lissek S, Biggs AL, Rabin SJ, Cornwell BR, Alvarez RP, Pine DS, Grillon C. 2008. Generalization of conditioned fear-potentiated startle in humans: Experimental validation and clinical relevance. Behav Res Ther 46: $678-687$.

Lovibond PF, Hanna SK, Siddle DAT, Bond NW. 1994. Electrodermal and subjective reactions to fear-relevant stimuli under threat of shock. $A u s$ I Psychol 46: $73-80$.

Milad MR, Orr SP, Pitman RK, Rauch SL. 2005. Context modulation of memory for fear extinction in humans. Psychophysiology 42: 456-464.

Mineka S, Ohman A. 2002. Phobias and preparedness: The selective, automatic, and encapsulated nature of fear. Biol Psych 52: 927-937.

Monfils M-H, Cowansage KK, Klann E, LeDoux JE. 2009. Extinction-reconsolidation boundaries: Key to persistent attenuation of fear memories. Science 324: 951-955.

Nader K, Hardt O. 2009. A single standard for memory: The case for reconsolidation. Nat Rev Neurosci 10: $224-234$.

Nader K, Schafe GE, LeDoux JE. 2000. Fear memories require protein synthesis in the amygdala for reconsolidation after retrieval. Nature 406: $722-726$.

Norrholm SD, Jovanovic T, Vervliet B, Myers K, Davis M, Rothbaum BO, Duncan EJ. 2006. Conditioned fear extinction and reinstatement in a human fear potentiated startle paradigm. Learn Mem 13: 681-685.

Orr SP, Metzger LJ, Lasko NB, Macklin ML, Peri T, Pitman RK. 2000. De novo conditioning in trauma-exposed individual with and without posttraumatic stress disorder. J Abn Psychol 109: 290-298.

Pedreira ME, Pérez-Cuesta KM, Maldonado H. 2004. Mismatch between what is expected and what actually occurs triggers memory reconsolidation or extinction. Learn Mem 11: 579-585.

Peterson RA, Reiss S. 1992. Anxiety sensitivity index manual. International Diagnostic Systems, Worthington, OH.

Pineles SL, Orr MR, Orr SP. 2009. An alternative scoring method for skin conductance responding in a differential fear conditioning paradigm with a long-duration conditioned stimulus. Psychophysiology 46: $1-12$.

Schiller D, Monfils M-H, Raio CM, Johnson DC, LeDoux JE, Phelps EA. 2010. Preventing the return of fear in humans using reconsolidation update mechanisms. Nature 663: 49-53.

Soeter M, Kindt M. 2010. Dissociation response systems: Erasing fear from memory. Neurobiol Learn Mem 94: 30-41.

Spielberger CD, Gorsuch RL, Lusthene RE. 1970. Manual for the state-trait anxiety inventory. Consulting Psychologists Press, Palo Alto, CA.

Squire LR, Stark CEL, Clark RE. 2004. The medial temporal lobe. Ann Rev Neurosci 27: 279-306.

Stegeren AH, Rohleder B, Everaerd W, Wolf OT. 2006. Salivary alpha amylase as marker for adrenergic activity during stress: Effect of beta blockade. Psychoneuroendocrinology 31: 137-141.

Suzuki A, Josselyn SA, Frankland PW, Masushige S, Silva AJ, Kida S. 2004 Memory reconsolidation and extinction have distinct temporal and biochemical signatures. J Neurosci 24: 4787-4795.

Thonberg H, Fredriksson JM, Nedergaard J, Cannon B. 2002. A novel pathway for adrenergic stimulation of cAMP-response-elementbinding protein (CREB) phosphorylation: Mediation via $\alpha_{1}$ adrenoceptors and protein kinase $\mathrm{C}$ activation. Biochem $\mathrm{J}$ 264: $73-79$.

Tronson NC, Taylor JR. 2007. Molecular mechanisms of memory reconsolidation. Nat Rev Neurosci 8: 262-275.

Walker MP. 2009. The role of sleep in cognition and emotion. Ann NY Acad Sci 1156: 168-197.

Weike AI, Schupp HT, Hamm AO. 2007. Fear acquisition requires awareness in trace but not delay conditioning. Psychophysiology 44: 170-180.

Received January 18, 2011; accepted in revised form March 14, 2011. 


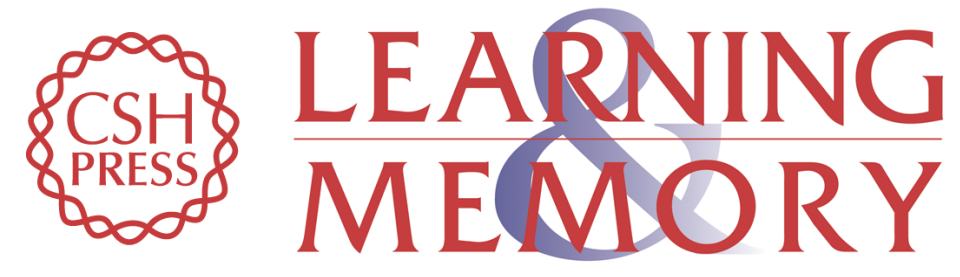

\section{Disrupting reconsolidation: Pharmacological and behavioral manipulations}

Marieke Soeter and Merel Kindt

Learn. Mem. 2011, 18:

Access the most recent version at doi:10.1101//m.2148511

Supplemental
Material http://learnmem.cshlp.org/content/suppl/2011/05/10/18.6.357.DC1

References This article cites 42 articles, 9 of which can be accessed free at: http://learnmem.cshlp.org/content/18/6/357.full.html\#ref-list-1

License

Email Alerting Receive free email alerts when new articles cite this article - sign up in the box at the Service top right corner of the article or click here. 